IZA DP No. 456

International Integration, Risk and the Welfare State

Torben M. Andersen

March 2002 


\title{
International Integration, Risk and the Welfare State
}

\author{
Torben M. Andersen \\ University of Aarhus, EPRU, CEPR and IZA, Bonn
}

Discussion Paper No. 456
March 2002

IZA

P.O. Box 7240

D-53072 Bonn

Germany

Tel.: +49-228-3894-0

Fax: +49-228-3894-210

Email: iza@iza.org

This Discussion Paper is issued within the framework of IZA's research area Internationalization of Labor Markets. Any opinions expressed here are those of the author(s) and not those of the institute. Research disseminated by IZA may include views on policy, but the institute itself takes no institutional policy positions.

The Institute for the Study of Labor (IZA) in Bonn is a local and virtual international research center and a place of communication between science, politics and business. IZA is an independent, nonprofit limited liability company (Gesellschaft mit beschränkter Haftung) supported by the Deutsche Post AG. The center is associated with the University of Bonn and offers a stimulating research environment through its research networks, research support, and visitors and doctoral programs. IZA engages in (i) original and internationally competitive research in all fields of labor economics, (ii) development of policy concepts, and (iii) dissemination of research results and concepts to the interested public. The current research program deals with (1) mobility and flexibility of labor, (2) internationalization of labor markets, (3) the welfare state and labor markets, (4) labor markets in transition countries, (5) the future of labor, (6) evaluation of labor market policies and projects and (7) general labor economics.

IZA Discussion Papers often represent preliminary work and are circulated to encourage discussion. Citation of such a paper should account for its provisional character. A revised version may be available on the IZA website (www.iza.org) or directly from the author. 
IZA Discussion Paper No. 456

March 2002

\section{ABSTRACT}

\section{International Integration, Risk and the Welfare State*}

How does international integration affect the welfare state? Does it call for a leaner or an expanded welfare state? International integration may affect the distortions caused by welfare state activities but also the risks motivating social insurance mechanisms. This paper addresses these potentially counteracting effects in a fully specified intertemporal twocountry stochastic endowment model focusing on the implications of product market integration reducing trade frictions across national product markets. It is shown that lower trade frictions may increase the marginal costs of public funds, which gives an argument for reducing (steady-state) public consumption. However, tighter integration of product markets unambiguously leads to more variability in private consumption, and this gives a case for expanding the social insurance provided via state-contingent public sector activities (automatic stabilizers).

JEL Classification: E30, F10, H11

Keywords: Trade frictions, risk-sharing, optimal public consumption, social insurance

Torben M. Andersen

Department of Economics

University of Aarhus

Building 326

DK-8000 Aarhus C

Denmark

Tel.: +458942 1609

Fax: +4586136334

Email: tandersen@econ.au.dk

\footnotetext{
* Comments by anonymous referees, the editors, Peter B. Sørensen, as well as participants at the EPRU workshop "Structural Change and European Economic Integration", the EEA conference in Bolzano, and seminar participants in Berlin, Bonn and Oslo are gratefully acknowledged.
} 


\section{Introduction}

The importance of international integration for the welfare state is vividly debated $^{1}$. To some international integration calls for a leaner welfare state partly to reduce tax distortions to maintain competitiveness and partly because the scope for risk diversification is improved and therefore reduces the need for social insurance supplied by the welfare state. To others the gains from international integration come at the cost of more volatility due to enhanced dependence on foreign economic developments and more heterogeneity in labour markets and the need for public sector activities in particular the provision of social insurance.

To evaluate these two divergent views, it is necessary to consider the interplay between international integration and public sector activities for both distortions and risk. Integration affects market interdependencies and therefore both distortions of public sector activities and the risk faced by society. The latter arises through mechanisms enhancing the exposure to foreign shocks as well as possible specialization of production tending to make the production structure less diversified ${ }^{2}$. On the other hand possibilities for risk diversification arise via both trade (especially in financial assets) and mobility of factors of production.

The present paper focuses on the fact that international integration enhances the possibilities for mutually advantageous trades while it at the same time enlarges the exposure to risk (foreign shocks) as well as creates possibilities for risk diversification (domestic shocks). Risk diversification may go through many routes in financial, labour and product markets, but here focus is on product markets for two reasons. First, one of the most important changes induced by international integration is the facilitation of trade and market (Coppel and Durand (1999)). Second, it is widely accepted that mobility of labour in a European context will play a modest role within a foreseeable future (OECD (1999)), and ample evidence indicates that financial markets do not - despite being closely integrated - reach the ideal with respect to risk diversification (see e.g. Lewis (1999)) $)^{3}$. Moreover, it is a central result in international trade theory that mobility of goods is suffi-

${ }^{1}$ For an introduction to the economics literature see e.g. Atkinson (1999) and Rodrik (1998), and to the political science literature see eg Swank (1999), Boix (1998) and EspingAndersen (1999).

${ }^{2}$ Frankel and Rose (1998) find in a recent empirical study that tighter integration tends to make business cycles more alike contradicting the "specialization hypothesis".

${ }^{3}$ While there is an increasing trend in the holdings of foreign assets, this is primarily for institutional investors, i.e. pension funds. Accordingly, this does not ensure full diversification of risks. Moreover, capital market problems in relation to human capital are not reduced due to international integration. 
cient to produce a situation equivalent to one where factors of production are mobile (the factor price equalization theorem). The present paper therefore focuses on mechanisms running via product markets, as a separate issue from increased mobility of factors of productions (and therefore tax bases) ${ }^{4}$.

Analysing the interrelationship between international integration and the exposure to risk involves aspects of both international trade and open macroeconomics. To this end a fully specified intertemporal two-country model with trade frictions is set up. Trade frictions do in practice take many forms including transportation costs, tariffs, information costs and administrative costs associated with e.g. product approval in foreign markets. Increased international integration is interpreted as a process which lowers (explicit and implicit) trade costs. While capital mobility is assumed perfect, capital markets are incomplete in the sense that it is not possible to fully diversify the consumption risk induced by domestic and foreign changes in production.

Different welfare states are distinguished by the extent to which the public sector mitigates risk (see e.g. Esping-Andersen $(1990,1999)$ ). In a broad interpretation of the welfare state we can thus include all public sector activities which affect the risk faced by society and its individuals as instruments for social risk diversification or insurance (Sandmo (1995)). The responses include reactions to both individual (idiosyncratic) risks and aggregate risks. Since international integration is likely to have consequences for the distribution of both idiosyncratic and aggregate risks it can have fundamental consequences for welfare states. The present paper focuses on aggregate risks for several reasons. Some aspects of international integration will affect all individuals in the same way, this applies in particular to changes originating in financial and goods markets. Since these are the areas in which international integration has proceeded the farthest, it is natural to start by analysing these. Moreover, aggregate shocks are likely to be most important for the overall size and structure of the welfare state, whereas a change in the distribution of idiosyncratic shocks ${ }^{5}$ across individuals may require restructuring, it is not necessarily going to affect the overall size of the public sector.

Despite the political interest in the issue of how the welfare state is af-

${ }^{4}$ This is not to deny the importance of this issue for welfare state activities, but to show that there are effects beyond those having to do with tax base mobility. See e.g. Sørensen (2000) for an interesting analysis of the implications of tax base mobility and references to the literature.

${ }^{5}$ To this may be added the more technical argument that a proper analysis of these problems requires an intertemporal general equilibrium model, and it is very difficult to construct a workable model with heterogeneous agents to study the role of idiosyncratic shocks. 
fected by international integration, the theoretical literature on this issue is very scant. Focussing on factor mobility Wildasin $(1995)^{6}$ argues in a static partial model that international integration reduces the need for social insurance since international mobility of production factors tends to work as a shock absorber at the same time as it reduces the scope for taxation since the tax base becomes more mobile. This supports the view that international integration may reduce both the need and scope for welfare state activities. Rodrik (1998) takes international integration as something leading to increased volatility of the terms of trade. To cope with this risk the public sector can be expanded so as to move resources away from sectors exposed to market risks. Rodrik also presents empirical evidence to the effect that more open economies tend to have a larger public sector which supports his conclusion that international integration calls for an expansion of public sector activities ${ }^{7}$. The present paper differs from the above-mentioned in two important respects. First, it is based on an explicit model of international trade in goods, and in this way captures basic gains from international trade as well as the exposure to risk. Second, the model is a fully-specified intertemporal two-country general equilibrium model focussing on product market integration.

The paper is organized as follows: Section 2 sets up the model, and the steady-state equilibrium is analysed in section 3 . In section 4 the interrelationship between international integration and the exposure to risk is explored while section 5 considers the role of social insurance. Finally, section 6 offers some concluding remarks. All proofs are collected in the appendices.

\section{An Intertemporal Two-Country Model with Trade Frictions}

Consider a non-monetary two-country model with specialized production, i.e. each country produces a separate commodity which can be traded internationally. The stock of domestic goods is denoted $y$, and of foreign goods $y^{*}$, to simplify production is assumed exogenous ${ }^{8}$. Trade across borders is assumed to be associated with trade frictions implying that one has to buy $1+\tau$ unit of the foreign good to attain one unit for final consumption, i.e.

${ }^{6}$ See Wildasin (2000) for the case with endogenous education with or without publicly financed education.

${ }^{7}$ In Rodrik (1997) mobility of capital is allowed for, and it is found that tax policy can compensate for the consequences of increased terms of trade risks induced by international integration provided that capital is not too mobile.

${ }^{8}$ Still there are distortions from fiscal policy, cf below. An exogenous production level implies that potential efficiency effects of social insurance are disregarded, cf Sinn (1995). 
$\tau(\geq 0)$ measures the friction associated with trade ("iceberg" costs) $)^{9}$. The process of international integration is taken to lower these trade frictions.

\section{Households}

The representative household has an infinite horizon and a utility function ${ }^{10}$ given as

$$
E_{t}\left[\sum_{j=0}^{\infty}(1+\delta)^{-j}\left(U\left(b_{t+j}\right)+w V\left(g_{t+j}\right)\right)\right]
$$

where $E_{t}$ denotes expectations conditional on period $t$ information, $\delta$ the subjective rate of time preference, and $U$ is the instantaneous utility function defined over private consumption $b$ as ${ }^{11}$

$$
U\left(b_{t+j}\right)=b_{t+j}-\frac{u}{2}\left(b_{t+j}\right)^{2} \quad u>0, \quad b<u^{-1}
$$

where $b$ is a composite index of consumption defined over consumption of home goods $(c)$ and foreign goods $\left(c^{*}\right)$, i.e.

$$
b_{t+j}=\frac{1}{a}\left(c_{t+j}\right)^{\alpha}\left(c_{t+j}^{*}\right)^{1-\alpha} \quad \frac{1}{2}<\alpha<1 \quad a \equiv \alpha^{\alpha}(1-\alpha)^{1-\alpha}
$$

Note that the assumption on $\alpha$ ensures a home bias in consumption in accordance with empirical facts. The strict concavity of the utility function implies risk aversion wrt. fluctuations in the consumption bundle. The utility of publicly provided services/goods is denoted $V\left(g_{t+j}\right)$ where $V^{\prime}>0$, $V^{\prime \prime}<0$, implying that there is also risk aversion wrt. variations in public consumption. The parameter $w(\geq 0)$ is a shorthand to capture the relative weight between private and public consumption. A society with a strong (political) preference for public consumption will thus have a high $w$.

Consider first how the household maximizes the value of the composite consumption bundle for given nominal expenditures $S_{t+j} \equiv P_{t+j} c_{t+j}+$ $P_{t+j}^{*}(1+\tau) c_{t+j}^{*}$ in period $t+j$, where $P_{t+j}$ is the price of home goods in the home market, and $P_{t+j}^{*}$ the price of the foreign product in the foreign market. The optimal consumption plan implies

$$
c_{t+j}=\alpha \frac{S_{t+j}}{P_{t+j}}
$$

${ }^{9}$ Note that $\tau$ is a pure friction and nobody derives any utility from this.

${ }^{10}$ This specification is also used in e.g. Glick and Rogoff (1995) and Razin (1995).

${ }^{11}$ This utility function is a convenient approximation allowing a mean-variance analysis in the case of uncertainty. The restriction on $b$ ensures that the marginal utility of consumption $b$ is positive. 


$$
c_{t+j}^{*}=(1-\alpha) \frac{S_{t+j}}{P_{t+j}^{*}(1+\tau)}
$$

The indirect utility implied by spending $S_{t+j}$ in period $t+j$ can be written

$$
b_{t+j}=\frac{S_{t+j}}{Q_{t+j}}
$$

where $Q$ is the consumer price index defined as

$$
Q_{t+j} \equiv\left(P_{t+j}\right)^{\alpha}\left(P_{t+j}^{*}(1+\tau)\right)^{1-\alpha}
$$

There is an international capital market in bonds with perfect capital mobility. Equilibrium in the financial market ensures that $\delta=r^{12}$, implying that the real rate of return is constant. Observe that there is a capital market imperfection since there is no trade in equities across countries, that is, domestic equities are held only by domestic residents (home bias in portfolio allocations). The risk associated with variations in production (income) can therefore not be fully diversified via the international capital market. While the specific assumptions on financial markets made here are highly stylized, they capture a basic capital market imperfection and maintain consistency with the observed "home bias" in international portfolio allocations (see Lewis (1999)). Note that the capital market still offers possibilities for risk diversification reflected in consumption smoothing, see below. The arguments made below on social insurance do not, therefore, rely on highly inefficient capital markets.

The budget constraint can now be written in real terms as

$$
\sum_{j=0}^{\infty}(1+\delta)^{-j} b_{t+j} \leq \sum_{j=0}^{\infty}(1+\delta)^{-j} i_{t+j}+f_{t}
$$

where real income is defined as $i_{t} \equiv I_{t} / Q_{t}$, where $I_{t}$ is the after-tax nominal income ( $\equiv P_{t} y_{t}-T_{t}$ ) and $T_{t}$ a lump-sum tax (see below). Real non-human wealth at the start of period $t$ is $f_{t}=F_{t} / Q_{t}$, where $F_{t}$ is nominal non-human wealth. It is convenient to define

$$
A_{t} \equiv \sum_{j=0}^{\infty}(1+\delta)^{-j} E_{t} i_{t+j}+f_{t}
$$

\footnotetext{
${ }^{12}$ It is well known that the unit elastic demand implies that the trade balance is unaffected by relative prices changes, see eg Obstfeld and Rogoff (2000). Accordingly, there is an equilibrium with the real rate of return equal to its steady state value determined by the time preference.
} 
as the household's expected total (human and non-human) wealth at time $t$. The intertemporal utility maximization problem has the simple solution ${ }^{13}$

$$
b_{t}=\frac{\delta}{1+\delta} A_{t}
$$

The household consumes the real return on its expected total wealth each period, and the martingale property holds for consumption and wealth, i.e.

$$
\begin{aligned}
& E_{t} b_{t+1}=b_{t} \\
& E_{t} A_{t+1}=A_{t}
\end{aligned}
$$

Consumption of the home and foreign goods can now be written

$$
\begin{aligned}
c_{t} & =\alpha \frac{\delta}{1+\delta} A_{t} \frac{Q_{t}}{P_{t}} \\
c_{t}^{*} & =(1-\alpha) \frac{\delta}{1+\delta} A_{t} \frac{Q_{t}}{P_{t}^{*}(1+\tau)}
\end{aligned}
$$

Note that demand is equal consumption for the home good $\left(d_{t}=c_{t}\right)$, while demand for the foreign good is $d_{t}^{*}=(1+\tau) c_{t}^{*}$ due to the trade friction. For later reference note also that risk associated with the consumption bundle $\left(b_{t}\right)$ arises from fluctuations in real wealth $\left(A_{t}\right)$.

\section{Government}

The government produces the public good by use of the home good as an input and finances these expenditures by a lump-sum tax. The public sector can access the international capital market on the same terms as private households implying Ricardian Equivalence and hence we can without loss of generality assume a balanced budget in each period, i.e.

$$
P_{t} g_{t}=T_{t}
$$

The home bias in public consumption captures the observed tendency of the public sector to consume home produced goods (services). The government is assumed to be utilitarian, i.e. the level of public consumption is set so as to maximize the utility function (1).

\section{Equilibrium condition}

The equilibrium in the home market reads

$$
y_{t}=d_{t}+\bar{d}_{t}^{*}+g_{t}
$$

where $\bar{d}_{t}^{*}$ denotes foreign demand of the home product.

${ }^{13}$ With the associated no ponzi game condition $\lim _{N \rightarrow \infty}(1+\delta)^{-N} f_{t+N}=0$. 


\section{Steady-State Equilibrium}

It is useful to start by analysing the properties of the steady-state equilibrium to this economy (see appendix A for details), and in particular how public consumption and thus the size of the public sector depends on trade frictions.

The private consumption bundle in steady-state equilibrium can be written as a function of home goods less home government consumption, foreign goods less foreign government consumption, and the trade friction $\tau$, i.e.

$$
b=b\left(y-g, y^{*}-g^{*}, \tau\right)
$$

There are gains to be reaped by international integration since lower trade frictions increase private consumption, i.e.

$$
\frac{\partial b}{\partial \tau}<0
$$

Fiscal policy distorts relative prices. Let $p\left(\equiv P^{*} / P\right)$ denote the relative price of foreign goods to domestic goods (terms of trade). In steady-state equilibrium an expansion in public consumption reduces the terms of trade

$$
\frac{\partial p}{\partial g}<0
$$

This "terms of trade" effect is well known to be crucial for interdependencies in fiscal policies in open economies, also with endogenous production ${ }^{14}$. It arises via a change in the relative composition of demand, in this case between foreign and domestic goods which are imperfect substitutes in private consumption, and therefore the government effectively tries to exercise some monopoly power over foreign consumers. A change in public consumption thus affects private consumption in two ways, namely, through the income effect induced by higher tax payments, and the distortion arising from a change in the terms of trade. Higher public consumption lowers private consumption, but the larger the trade friction the less a given expansion in public consumption reduces private consumption, i.e.

$$
\frac{\partial b}{\partial g}<0 \quad ; \quad \frac{\partial}{\partial \tau}\left(\frac{\partial b}{\partial g}\right)>0
$$

The reason is that the larger the trade friction, the less the private consumption generated out of a given income (wealth). The reduction in income

\footnotetext{
${ }^{14}$ For models with no labour market distortions see eg van der Ploeg (1987), Turnovsky (1988) and Devereux (1991), and with distorted labour markets see Andersen, Rasmussen and Sørensen (1996).
} 
(wealth) due to increased public consumption thus has a smaller effect on private consumption the larger the trade friction. This suggests that trade frictions are conducive to choosing a high level of public consumption.

The interrelationship between trade frictions and the optimal level of public consumption is, however, less straightforward since ${ }^{15}$

Proposition 1 In a symmetric steady-state equilibrium the optimal level of public consumption is (i) increasing in the trade friction $(\tau)$ if $w \geq \bar{w}$ and (ii) decreasing in the trade friction $(\tau)$ for $\tau<\underline{\tau}$ and increasing for $\tau>\underline{\tau}$ if $w<\bar{w}$.

The reason for the ambiguity is that a change in the trade friction affects the optimal level of public consumption via two routes. First, lower trade frictions imply that a change in public consumption has a larger effect on private consumption and this tends to lower the optimal level of public consumption, $\mathrm{cf}(7)$. Second, lower trade frictions increase private consumption, cf (6) and thereby lower the marginal utility of private consumption. This tends to increase the optimal level of public consumption.

If there is a strong preference for public goods $(w \geq \bar{w})$, lower trade frictions unambiguously lead to a lower steady-state level of public consumption. However, with a less strong preference for public goods $(w<\bar{w})$, international integration induces a higher level of public consumption (for $\tau \leq \underline{\tau}$ ).

Proposition 1 implies that there may be convergence in public consumption in the sense that product market integration makes countries with a strong preference for public consumption (and therefore ceteris paribus a large public sector) reduce public consumption, and vice versa for countries with a less strong preference for public consumption. This runs counter to the argument made by many political scientists that strong regime persistence implies that there is strong opposition to changes in welfare arrangements, which prevents convergence in relative public sector sizes (see e.g. Boix (1998), Esping-Andersen (2000) and Swank (1999)).

\section{Risk}

Turning to an analysis of how international product market integration affects the exposures to risk, we now add uncertainty by assuming that production is stochastic. Specifically, it is assumed that $\widetilde{y}_{t} \equiv y_{t}-y$, i.e. the deviation of output from its mean (= steady-state value) has an expected value of zero

${ }^{15}$ This gives the non-cooperative equilibrium. It is well known that due to the terms of trade effect, the non-cooperative level of public consumption exceeds the cooperative level, see the same references as in the previous footnote. 
and a variance $\sigma^{2}$, and similarly for the foreign country ${ }^{16}$. The contemporary correlation is denoted $\rho$, but the shocks are uncorrelated over time (transitory shocks $)^{17}$. The information set in period $t$ is $\psi_{t}$. The results reported below are derived for a version of the model linearized around the symmetric steadystate equilibrium (see appendix B) which can be solved analytically.

The first and obvious implication is that variations in output cause variations in consumption. We have that

$$
\frac{\partial \widetilde{b}_{t}}{\partial \widetilde{y}_{t}^{*}}>0 ; \frac{\partial \widetilde{b}_{t}}{\partial \widetilde{y}_{t}}>0
$$

and

$$
\frac{\partial \widetilde{b}_{t}}{\partial \widetilde{y}_{t}^{*}}<\frac{\partial \widetilde{b}_{t}}{\partial \widetilde{y}_{t}}
$$

Higher output of both the home and the foreign product implies higher consumption, but the sensitivity is larger to domestic output than to foreign output. Trade frictions affect the sensitivity of consumption to output, and we have that

Proposition 2 The larger the trade frictions $(\tau)$, the lower the sensitivity of consumption to both domestic and foreign output variations. Consumption is more sensitive to domestic than foreign production, and the more so, the larger the trade friction.

The first part of this result reflects that trade frictions introduce a wedge between consumption and production. The larger the trade frictions the larger the wedge, and this reduces the sensitivity of consumption to variations in both domestic and foreign production. Secondly, larger trade frictions tend to bias consumption towards domestic goods, which makes consumption more sensitive to domestic rather than foreign production $^{18}$.

The welfare effect of variations in output depends on the variability of private consumption, and since agents are assumed risk averse they are worse off the more consumption varies. We have ${ }^{19}$

\footnotetext{
${ }^{16}$ Notice that the utility function implies that a two-moment or mean-variance analysis is sufficient.

${ }^{17}$ See e.g. Stockman and Tesar (1995) for some empirical regularities on business cycle movements and a two-country model with complete capital markets.

${ }^{18}$ Note that $c / c^{*}$ is increasing in $\tau$. However, $c / c^{*}(1+\tau)$ is independent of $\tau$ due to the unit elastic demand function.

${ }^{19}$ It can be shown that the variability of the terms of trade is decreasing in the trade friction, cf the conjecture made by Rodrik (1997, 1998). However, this does not have any direct welfare effects.
} 
Proposition 3 The variability of private consumption (Var $\left(\widetilde{b}_{t} \mid \psi_{t-1}\right)$ ) is (i) unambiguously increasing in the correlation coefficient between domestic and foreign production $(\rho)$, and (ii) decreasing in the trade friction $(\tau)$ for $\rho \geq \underline{\rho}(<0)$.

The first part shows that there is some risk diversification running via product markets, and the less the correlation in output variations across countries the lower the variability of consumption. This is in accordance with standard principles for risk diversification ${ }^{20}$. The second part shows that lower trade frictions lead to higher consumption variability. The reason being that trade frictions work as a shock absorber (provided that the correlation coefficient is not too low) between production and consumption, and the lower the friction the less the absorption. Since lower trade frictions also increase the mean of consumption (see section 3) we find that trade frictions lower both the mean and variance of consumption, and the welfare effects are thus in general ambiguous.

It might be conjectured that the exposure of private consumption to risk depends on the level of public consumption, which would imply that the relative size of the public sector affects the exposure of the economy to risk. We have, however, that ${ }^{21}$

Proposition 4 The probability distribution of private consumption is independent of the symmetric steady-state level of public consumption.

That is, the steady-state level of public consumption affects the average level of private consumption but not its variability. Given that the size of the public sector does not in itself change the risk profile (cf Rodrik (1998)) it becomes of interest to ask whether there are other ways of coping with the exposure to risk accompanying further international integration.

\section{Social Insurance}

Given that international integration leads to more aggregate risks, it is natural to question whether this leaves a greater role for (implicit) social insur-

\footnotetext{
${ }^{20}$ Frankel and Rose (1998) present evidence that stronger trade links tend to increase the correlation in output fluctuations between two countries. Hence, international integration may have a separate effect by increasing the correlation coefficient $\rho$.

${ }^{21}$ This result obviously depends on the linearization, and it thus says that there are no first-order effects of variations in the steady-state level of public consumption on the volatility of private consumption. Note, that this validates the approach of analysing state contingencies (see below) from the steady-state level.
} 
ance, that is, is there a case for an active management (state contingencies) of public sector activities so as to affect the risk profile of private consumption?

Since the present model assumes a balanced budget it is impossible to distinguish between contingencies in public consumption and taxation, or to put it differently, given Ricardian Equivalence risk diversification via the public budget is not possible ${ }^{22}$. Hence, the following shows that even a very restricted form of contingencies in public sector activities can have potentially beneficial welfare effects.

State contingencies can be made in several ways, and it is beyond the scope of the present paper to analyse the optimal way by which to design such contingencies. The aim is to show that such contingencies can lead to welfare improvements even if they take a very simple (ad hoc) form, and to analyse how the need for social insurance is affected by international integration. Assume for the sake of argument that public consumption/taxation is made contingent on private consumption, i.e.

$$
\widetilde{g}_{t}=\kappa \widetilde{b}_{t}
$$

where $\kappa$ measures the degree of contingency in public consumption. This is equivalent to making a contingency on wealth, $\mathrm{cf}$ (3). An obvious alternative would be to make the contingency on current income, but the qualitative implications would be the same ${ }^{23}$.

It can be established that (see appendix C)

$$
\frac{\partial}{\partial \kappa}\left(\frac{\partial \widetilde{b}_{t}}{\partial \widetilde{y}_{t}}\right)<0 ; \frac{\partial}{\partial \kappa}\left(\frac{\partial \widetilde{b}_{t}}{\partial \widetilde{y}_{t}^{*}}\right)<0
$$

that is, more sensitivity of public consumption to the business cycle situation makes private consumption less sensitive to changes in both domestic and foreign output. This implies

Proposition 5 The variability of private consumption is decreasing in $\kappa$ for $\rho \geq \underline{\rho}^{p}<0$.

This shows that the choice of contingencies in public sector activities affects the risk profile faced by agents. In the particular form considered here we find that the risk of private consumption is reduced the larger the

\footnotetext{
${ }^{22}$ See Andersen and Dogonowski (2001) for an analysis of how contingencies in the budget balance can provide social insurance in the absence of Ricardian Equivalence.

${ }^{23}$ The first version of this paper assumed an income contingency, and the qualitative results are the same. However, the analysis of the optimal choice of the policy parameter $\kappa$ is much more complicated in this case.
} 
policy parameter $\kappa$. This implies that there would be $(\kappa>0)$ a pro-cyclical variation such that resources absorbed by the public sector should be higher when private consumption (income/wealth) is high and vice versa ${ }^{2425}$.

The pro-cyclical nature of the contingency may at first seem counterintuitive. However, the way private consumption can be stabilized is by stabilizing wealth and therefore in turn disposable income. To stabilize disposable income requires that tax payments are high when income is unexpectedly high, and vice versa. The balanced budget constraint implies a one-to-one relation between changes in public consumption and taxes and therefore public consumption has to change pro-cyclically to stabilize disposable income. It is therefore perhaps best to think of the effect underlying proposition 5 as running via the tax effect rather than the expenditure effect. This corresponds fairly closely to the automatic stabilizers discussed at great length in the macroeconomic literature, and it is also empirically well established that taxation is highly pro-cyclical (van der Noord (2000)).

Given that contingencies in public consumption provide a form of social insurance the question is how such policies are affected by product market integration. To see the basic effects involved we have

Proposition 6 The larger the trade friction $(\tau)$, the smaller the contingency in public consumption $(\kappa)$ needed to attain a given stabilization of private consumption, i.e.

$$
\left.\frac{\partial \kappa}{\partial \tau}\right|_{\operatorname{Var}\left(\widetilde{b}_{t} \mid \psi_{t-1}\right)}<0 \quad \text { for } \quad \rho>\underline{\rho}^{p}(<0)
$$

To attain a given variability in private consumption it is necessary to strengthen contingencies in public consumption (social insurance) if trade frictions are reduced (provided the shocks are not too negatively correlated). This can be taken to support the view that international integration may strengthen the need for implicit insurance provided by the public sector.

Although private consumption becomes less volatile via the contingency built into public consumption, it obviously implies that public consumption becomes more volatile. It is thus reasonable to ask whether contingencies in public consumption achieve anything but to substitute public consumption volatility for private consumption volatility. To address this issue in more detail we have to specify the utility function for public consumption further,

${ }^{24}$ See Andersen and Holden (2001) for the optimal response of public consumption to supply and demand shocks in a small open economy.

${ }^{25}$ Empirical evidence indicates that this is indeed the case since the public budget balance is strongly pro-cyclical, see eg OECD (1993) and Braconier and Holden (1999). 
and it is assumed that it has a form similar to the utility function for private consumption, i.e.

$$
V\left(g_{t+j}\right)=g_{t+j}-\frac{v}{2}\left(g_{t+j}\right)^{2} \quad v>0, g<v^{-1}
$$

Note that since the steady-state level of private and public consumption (and hence their expected values are given) it follows that the choice of the stabilization parameter $(\kappa)$ maximization of the welfare function (1) given the specification of the $V$-function above is equivalent to the choice minimizing

$$
\operatorname{Var}\left(\widetilde{b}_{t} \mid \psi_{t-1}\right)+\pi \operatorname{Var}\left(\widetilde{g}_{t} \mid \psi_{t-1}\right)
$$

where $\pi=w v u^{-1}$ effectively measures the degree of substitution between "private" and "public" risk.

Proposition 7 The choice of the contingency parameter $\kappa$ minimizing (8) is strictly positive, decreasing in $\pi$, and increasing in $\rho$. For $\rho \in[0,1]$ we have that $\alpha \geq \underline{\alpha}$ is a sufficient condition that lower trade frictions increase the stabilization parameter.

There is thus a welfare case for state-contingent public sector activities or automatic stabilizers $(\kappa>0)$ implying that public resource absorption is pro-cyclical. It is hardly surprising that the larger weight given to risk in public consumption $(\pi)$ the lower the contingency parameter $(\kappa)$. A higher correlation $(\rho)$ between domestic and foreign production reduces the possibilities for risk diversification in private consumption, and therefore increases the optimal choice of the contingency parameter. Finally, when the home bias in consumption is sufficiently large, lower trade frictions call for a policy response strengthening the contingency in public activities. Observe that while proposition 1 concerns the steady-state level of public consumption, proposition 6 concerns contingencies and implies that stronger contingencies or stronger elements of social insurance should be built into public sector activities when economies integrate.

\section{Concluding Remarks}

The present analysis has shown that international integration of product markets has implications both for the level and contingencies built into the public sector. The analysis has shown that two popular views on the relation between public sector activities and international integration both capture aspects which are supported by theoretical considerations. The supporters of 
the "Rolling back" view may be right that the distortions induced by public sector activities may be larger the smaller the trade frictions and therefore integration calls for a smaller public sector. On the other hand supporters of the "globalization" view are right that tighter international integration may increase volatility and call for more social insurance achieved via statecontingent public activities. This can be achieved by expanding so-called automatic stabilizers in the public budget running via both the revenue and the expenditure side. It is worth stressing that the results on social insurance found here are based on a model with forward-looking agents and perfect capital mobility, albeit the capital market is not complete in the sense of offering a set of assets contingent on all possible states of nature.

On the agenda for future research are extensions addressing two important shortcomings of the present model. First, specific functional forms have been useful to arrive at analytical results, but raise a question of robustness. Hence, it is of interest to generalize the structure of the model. Second, while it is straightforward to endogenize production, it would only really be interesting in a setting admitting unemployment potentially allowing for both aggregate and idiosyncratic risks, and also insurance mechanisms in the labour market (Agell(1999)).

\section{Appendix A: Steady-State Equilibrium}

The equilibrium condition for the home product market reads

$$
y_{t}=\alpha \frac{\delta}{1+\delta} A_{t} \frac{Q_{t}}{P_{t}}+(1-\alpha) \frac{\delta}{1+\delta} A_{t}^{*} \frac{Q_{t}^{*}}{P_{t}}+g_{t}
$$

Using that in steady state $A=\frac{1+\delta}{\delta} \frac{P}{Q}(y-g)$ where the time subscript is eliminated to indicate steady state and initial non-human wealth is assumed equal to zero, we get

$$
y-g=\alpha(y-g)+(1-\alpha)\left(y^{*}-g^{*}\right)\left(\frac{P^{*}}{P}\right)
$$

implying that the terms of trade $p$ is determined by

$$
p \equiv \frac{P^{*}}{P}=\frac{y-g}{y^{*}-g^{*}}
$$

and hence equals one in a symmetric steady state. It follows that

$$
\frac{P}{Q}=\left(\frac{P}{P^{*}} \frac{1}{1+\tau}\right)^{1-\alpha}=(y-g)^{\alpha-1}\left(y^{*}-g^{*}\right)^{1-\alpha}(1+\tau)^{\alpha-1}
$$

Using that $b=\frac{\delta}{1+\delta} A=\frac{P}{Q}(y-g)$ we have that

$$
b=(y-g)^{\alpha}\left(y^{*}-g^{*}\right)^{1-\alpha}(1+\tau)^{\alpha-1}
$$


and therefore

$$
\frac{\partial b}{\partial g}=-\alpha(y-g)^{\alpha-1}\left(y^{*}-g^{*}\right)^{1-\alpha}(1+\tau)^{\alpha-1}
$$

\section{Proof Proposition 1:}

Optimal steady-state public consumption solves

$$
\max _{g} U(b)+w V(g)
$$

Hence, the first order condition reads in symmetric equilibrium

$$
w V_{g}(g)=-U_{b}(b) \frac{\partial b}{\partial g} \equiv \chi(g, \tau)
$$

Evaluating the marginal costs of public consumption, we have

$$
\chi(g, \tau) \equiv \alpha\left(1-k(y-g)(1+\tau)^{\alpha-1}\right)(1+\tau)^{\alpha-1}
$$

The second order condition reads

$$
w V_{g g}(g)-\chi_{g}(g, \tau) \leq 0
$$

We have that

$$
\frac{\partial g}{\partial \tau}=\frac{\chi_{\tau}(g, \tau)}{w V_{g g}(g)-\chi_{g}(g)}
$$

Hence,

$$
\operatorname{sign}\left(\frac{\partial g}{\partial \tau}\right)=-\operatorname{sign} \chi_{\tau}=\operatorname{sign}\left(1-2 k(y-g)(1+\tau)^{\alpha-1}\right)
$$

The expression on the right hand side is increasing in $\tau$ and $g$. Note that

$$
1-2 k(y-g)(1+\tau)^{\alpha-1} \rightarrow 1 \quad \text { for } \tau \rightarrow \infty
$$

Denote by $g_{0}$ the optimal level of public consumption in the absence of trade frictions $(\tau=0)$, i.e. $g_{0}$ solves

$$
w V_{g}\left(g_{0}\right)=\chi\left(g_{0}, 0\right)
$$

If $g_{0}>\bar{g}_{0} \equiv y-(2 k)^{-1}$, it follows that $1-2 k(y-g)(1+\tau)^{\alpha-1}>0$ for all values of $\tau \geq 0$, and hence $\partial g / \partial \tau>0$. If $g_{0}<\bar{g}_{0}$, we have that $\partial g /\left.\partial \tau\right|_{\tau=0}<$ 0 . However, since the expression in (10) is increasing in $\tau$, it follows that there exists a $\underline{\tau}>0$ such that $\partial g / \partial \tau<0$ for $\tau \leq \underline{\tau}$ and $\partial g / \partial \tau<0$ for $\tau>\underline{\tau}$. Proposition 1 follows by noting that $g_{0}$ is increasing in $w$. 


\section{Appendix B: Stochastic Equilibrium}

From (2) it follows straightforwardly that

$$
\widetilde{A}_{t}=\sum_{j=0}^{\infty}(1+\delta)^{-j} E_{t} \widetilde{i}_{t+j}+\widetilde{f}_{t}
$$

where $\widetilde{a}$ denotes that the variables are measured in deviations from steadystate equilibrium. From (3) we have

$$
\widetilde{b}_{t}=\frac{\delta}{1+\delta} \widetilde{A}_{t}
$$

Making a first-order approximation of (9) around a symmetric steadystate equilibrium and assuming public consumption to be constant, we can write the equilibrium condition for the goods market

$$
\widetilde{y}_{t}=\eta_{d A} \widetilde{A}_{t}+\eta_{d A^{*}} \widetilde{A}_{t}^{*}+\eta_{d p} \widetilde{p}_{t}
$$

where

$$
\begin{aligned}
& \eta_{d A}=\alpha \frac{\delta}{1+\delta}(1+\tau)^{1-\alpha} \quad ; \quad \eta_{d A^{*}}=(1-\alpha) \frac{\delta}{1+\delta}(1+\tau)^{1-\alpha} \\
& \eta_{d p}=2 \alpha(1-\alpha) \frac{\delta}{1+\delta}(1+\tau)^{1-\alpha} A .
\end{aligned}
$$

Note for later reference that

$$
\frac{\partial \eta_{d A}}{\partial \tau}>0 ; \frac{\partial \eta_{d A^{*}}}{\partial \tau}>0 \quad ; \quad \frac{\partial \eta_{d p}}{\partial \tau}>0
$$

Real income is defined as ( $g$ constant)

$$
i_{t}=\frac{P_{t}}{Q_{t}}\left(y_{t}-g\right)
$$

Hence, to a first order approximation we have

$$
\widetilde{i}_{t}=\eta_{I y} \widetilde{y}_{t}-\eta_{I p} \widetilde{p}_{t}
$$

where

$$
\eta_{I y}=(1+\tau)^{\alpha-1} \quad ; \quad \eta_{I p}=(1-\alpha)(y-g)(1+\tau)^{\alpha-1}
$$

Hence,

$$
\frac{\partial \eta_{I y}}{\partial \tau}<0 \quad ; \quad \frac{\partial \eta_{I p}}{\partial \tau}<0
$$


Inserting from (13) we get

$$
\widetilde{i}_{t}=\left(\eta_{I y}-\frac{\eta_{I p}}{\eta_{d p}}\right) \widetilde{y}_{t}+\frac{\eta_{I p} \eta_{d A}}{\eta_{d p}} \widetilde{A}_{t}+\frac{\eta_{I p} \eta_{d A^{*}}}{\eta_{d p}} \widetilde{A}_{t}^{*}
$$

where

$$
\begin{aligned}
& \eta_{I y}-\frac{\eta_{I p}}{\eta_{d p}}=\frac{(2 \alpha-1)}{2 \alpha}(1+\tau)^{\alpha-1}>0 \quad \text { for } \alpha>\frac{1}{2} \\
& \frac{\eta_{I p} \eta_{d A}}{\eta_{d p}}=\frac{1}{2} \frac{\delta}{1+\delta} \quad ; \quad \frac{\eta_{I p} \eta_{d A^{*}}}{\eta_{d p}}=\frac{(1-\alpha)}{2 \alpha} \frac{\delta}{1+\delta}
\end{aligned}
$$

Using (11), (15) and $E_{t} \widetilde{y}_{t+j}=0, E_{t} \widetilde{A}_{t+j}=\widetilde{A}_{t} \forall j>0$ we get

$$
\widetilde{A}_{t}=\left(\eta_{I y}-\frac{\eta_{I p}}{\eta_{d p}}\right) \widetilde{y}_{t}+\frac{1+\delta}{\delta} \frac{\eta_{I p}}{\eta_{d p}}\left(\eta_{d A} \widetilde{A}_{t}+\eta_{d A^{*}} \widetilde{A}_{t}^{*}\right)+\widetilde{f}_{t}
$$

Similarly for the foreign country we have (note coefficients are not country specific since the approximation is made around a symmetric steady state equilibrium)

$$
\begin{aligned}
& \widetilde{y}_{t}^{*}=\eta_{d A^{*}} \widetilde{A}_{t}+\eta_{d A} \widetilde{A}_{t}^{*}-\eta_{d p} \widetilde{p}_{t} \\
& \widetilde{i}_{t}^{*}=\left(\eta_{I y}-\frac{\eta_{I p}}{\eta_{d p}}\right) \widetilde{y}_{t}^{*}+\frac{\eta_{I p} \eta_{d A}}{\eta_{d p}} \widetilde{A}_{t}^{*}+\frac{\eta_{I p} \eta_{d A^{*}}}{\eta_{d p}} \widetilde{A}_{t}
\end{aligned}
$$

It follows that

$$
\widetilde{A}_{t}^{*}=\left(\eta_{I y}-\frac{\eta_{I p}}{\eta_{d p}}\right) \widetilde{y}_{t}^{*}+\frac{1+\delta}{\delta}\left(\frac{\eta_{I p} \eta_{d A}}{\eta_{d p}} \widetilde{A}_{t}^{*}+\frac{\eta_{I p} \eta_{d A^{*}}}{\eta_{d p}} \widetilde{A}_{t}\right)+\widetilde{f}_{t}^{*}
$$

We can now summarize the model in the following two equations

$$
\begin{aligned}
& \widetilde{A}_{t}=\Gamma_{A y} \widetilde{y}_{t}+\Gamma_{A A} \widetilde{A}_{t}^{*}+\Gamma_{A f} \widetilde{f}_{t} \\
& \widetilde{A}_{t}^{*}=\Gamma_{A y} \widetilde{y}_{t}^{*}+\Gamma_{A A} \widetilde{A}_{t}+\Gamma_{A f} \widetilde{f}_{t}^{*}
\end{aligned}
$$

where

$$
\begin{aligned}
& \Gamma_{A y}=\left(\eta_{I y}-\frac{\eta_{I p}}{\eta_{d p}}\right)\left(1-\frac{1+\delta}{\delta} \frac{\eta_{I p} \eta_{d A}}{\eta_{d p}}\right)^{-1}=\left(\frac{2 \alpha-1}{\alpha}\right)(1+\tau)^{\alpha-1}>0 \quad \text { for } \quad \alpha>\frac{1}{2} \\
& \Gamma_{A A}=\frac{1+\delta}{\delta} \frac{\eta_{I p} \eta_{d A^{*}}}{\eta_{d p}}\left(1-\frac{1+\delta}{\delta} \frac{\eta_{I p} \eta_{d A}}{\eta_{d p}}\right)^{-1}=\frac{1-\alpha}{\alpha}<1 \quad \text { for } \quad \alpha>\frac{1}{2}
\end{aligned}
$$




$$
\Gamma_{A f}=\left(1-\frac{1+\delta}{\delta} \frac{\eta_{I p} \eta_{d A}}{\eta_{d p}}\right)^{-1}=2
$$

Note for later reference that $\frac{\partial \Gamma_{A y}}{\partial \tau}<0$ and $\frac{\partial \Gamma_{A A}}{\partial \tau}=0$. It follows that $\frac{\partial \widetilde{A_{t}}}{\partial \widetilde{y_{t}}}>\frac{\partial \widetilde{A_{t}}}{\partial \overline{y t}_{t}^{*}}$ since

$$
\begin{aligned}
& \frac{\partial \widetilde{A_{t}}}{\partial \widetilde{y_{t}}} \equiv \eta_{A y}=\left(1-\Gamma_{A A}^{2}\right)^{-1} \Gamma_{A y}>0 \quad ; \quad \frac{\partial \eta_{A y}}{\partial \tau}<0 \\
& \frac{\partial \widetilde{A_{t}}}{\partial \widetilde{y_{t}^{*}}} \equiv \eta_{A y^{*}}=\left(1-\Gamma_{A A}^{2}\right)^{-1} \Gamma_{A y} \Gamma_{A A}>0 \quad ; \frac{\partial \eta_{A y^{*}}}{\partial \tau}<0
\end{aligned}
$$

Proof Proposition 3:

Using (12) we have to consider

$$
\operatorname{Var}\left(\widetilde{A}_{t} \mid \psi_{t-1}\right)=\left(\left(\eta_{A y}\right)^{2}+\left(\eta_{A y^{*}}\right)^{2}+2 \rho \eta_{A y} \eta_{A y^{*}}\right) \sigma^{2}
$$

Hence,

$$
\frac{\partial \operatorname{Var}\left(\widetilde{A}_{t} \mid \psi_{t-1}\right)}{\partial \tau}=2\left(\left(\eta_{A y}+\rho \eta_{A y^{*}}\right) \frac{\partial \eta_{A y}}{\partial \tau}+\left(\eta_{A y^{*}}+\rho \eta_{A y}\right) \frac{\partial \eta_{A y^{*}}}{\partial \tau}\right) \sigma^{2}
$$

Since

$$
\eta_{A y}+\rho \eta_{A y^{*}}>0 \quad \text { for } \quad \rho \in[-1,1]
$$

and

$$
\eta_{A y^{*}}+\rho \eta_{A y} \geq 0 \quad \text { for } \quad \rho \geq \underline{\rho} \equiv-\frac{\eta_{A y^{*}}}{\eta_{A y}}=-\Gamma_{A A}=\frac{\alpha-1}{\alpha}<0
$$

it can be concluded that

$$
\frac{\partial \operatorname{Var}\left(\widetilde{A}_{t} \mid \psi_{t-1}\right)}{\partial \tau}<0 \quad \text { for } \rho>\underline{\rho}
$$

Finally, it follows directly that $\frac{\partial \operatorname{Var}\left(\widetilde{A}_{t} \mid \psi_{t-1}\right)}{\partial \rho}>0$.

Proof Proposition 4:

Since $\frac{\partial \eta_{A y}}{\partial g}=0$ and $\frac{\partial \eta_{A y^{*}}}{\partial g}=0$ it follows directly that the equilibrium distribution for the private consumption bundle is independent of the steady-state level of public consumption. 


\section{Appendix C: state-contingent Public Consumption}

With state-contingent public consumption we have that the product market equilibrium condition reads

$$
\widetilde{y}_{t}=\eta_{d A} \widetilde{A}_{t}+\eta_{d A^{*}} \widetilde{A}_{t}^{*}+\eta_{d p} \widetilde{p}_{t}+\widetilde{g}_{t}
$$

assuming $\widetilde{g}_{t}=\kappa \widetilde{b}_{t}$ and using the approximation

$$
\widetilde{i}_{t}=\eta_{I y}\left(\widetilde{y}_{t}-\widetilde{g}_{t}\right)-\eta_{I p} \widetilde{p}_{t}
$$

we get

$$
\widetilde{i}_{t}=\left(\eta_{I y}-\frac{\eta_{I p}}{\eta_{d p}}\right) \widetilde{y}_{t}+\left[\frac{\eta_{I p} \eta_{d A}}{\eta_{d p}}-\kappa\left(\eta_{I y}-\frac{\eta_{I p}}{\eta_{d p}}\right) \frac{\delta}{1+\delta}\right] \widetilde{A}_{t}+\frac{\eta_{I p} \eta_{d A^{*}}}{\eta_{d p}} \widetilde{A}_{t}^{*}
$$

It follows that we can write (the $p$ indicates that coefficients are dependent on the policy rule)

$$
\widetilde{A}_{t}=\Gamma_{A y}^{p} \widetilde{y}_{t}+\Gamma_{A A}^{p} \widetilde{A_{t}^{*}}+\Gamma_{A f}^{p} \widetilde{f}_{t}
$$

where

$$
\begin{aligned}
& \Gamma_{A y}^{p}=\left(\eta_{I y}-\frac{\eta_{I p}}{\eta_{d p}}\right)\left(1-\frac{1+\delta}{\delta} \frac{\eta_{I p} \eta_{d A}}{\eta_{d p}}+\kappa\left(\eta_{I y}-\frac{\eta_{I p}}{\eta_{d p}}\right)\right)^{-1}=\frac{\left(\frac{2 \alpha-1}{2 \alpha}\right)(1+\tau)^{\alpha-1}}{\frac{1}{2}+\kappa\left(\frac{2 \alpha-1}{2 \alpha}\right)(1+\tau)^{\alpha-1}}>0 \\
& \Gamma_{A A}^{p}=\frac{1+\delta}{\delta} \frac{\eta_{I p} \eta_{d A^{*}}}{\eta_{d p}}\left(1-\frac{1+\delta}{\delta} \frac{\eta_{I p} \eta_{d A}}{\eta_{d p}}+\kappa\left(\eta_{I y}-\frac{\eta_{I p}}{\eta_{d p}}\right)\right)^{-1}=\frac{\frac{1-\alpha}{2 \alpha}}{\frac{1}{2}+\kappa\left(\frac{2 \alpha-1}{2 \alpha}\right)(1+\tau)^{\alpha-1}}>0 \\
& \Gamma_{A f}^{p}=\left(1-\frac{1+\delta}{\delta} \frac{\eta_{I p} \eta_{d A}}{\eta_{d p}}+\kappa\left(\eta_{I y}-\frac{\eta_{I p}}{\eta_{d p}}\right)\right)^{-1}=\frac{1}{\frac{1}{2}+\kappa\left(\frac{2 \alpha-1}{2 \alpha}\right)(1+\tau)^{\alpha-1}}>0
\end{aligned}
$$

It can be shown that

$$
\begin{aligned}
& \frac{\partial \Gamma_{A y}^{p}}{\partial \kappa}<0 ; \frac{\partial \Gamma_{A A}^{p}}{\partial \kappa}<0 \\
& \frac{\partial \Gamma_{A y}^{p}}{\partial \tau}<0 ; \frac{\partial \Gamma_{A A}^{p}}{\partial \tau}>0 \\
& \frac{\partial}{\partial \tau} \frac{\partial \Gamma_{A y}^{p}}{\partial \kappa}>0 ; \frac{\partial}{\partial \tau} \frac{\partial \Gamma_{A A}^{p}}{\partial \kappa}>0
\end{aligned}
$$

For later reference note

$$
\varepsilon_{\Gamma_{A y}^{p}, \kappa}=\varepsilon_{\Gamma_{A A}^{p}, \kappa}=-\frac{\kappa\left(\frac{2 \alpha-1}{2 \alpha}\right)(1+\tau)^{\alpha-1}}{\frac{1}{2}+\kappa\left(\frac{2 \alpha-1}{2 \alpha}\right)(1+\tau)^{\alpha-1}}<0
$$


and $\frac{\partial \varepsilon_{\Gamma_{A y}}^{p}, \kappa}{\partial \tau}>0$. For the foreign country we have similarly

$$
\widetilde{A}_{t}^{*}=\Gamma_{A y}^{p *} \widetilde{y}_{t}^{*}+\Gamma_{A A}^{p *} \widetilde{A}_{t}+\Gamma_{A f}^{p *} \widetilde{f}_{t}^{*}
$$

where $\Gamma_{A y}^{p *}, \Gamma_{A A}^{p *}$, and $\Gamma_{A f}^{p *}$ are defined similarly to the coefficients for the home country, with the exception that the policy parameter is $\kappa^{*}$ for the foreign country. It follows that

$$
\begin{aligned}
& \frac{\partial \widetilde{A}_{t}}{\partial \widetilde{y}_{t}} \equiv \eta_{A y}^{p}=\left(1-\Gamma_{A A}^{p} \Gamma_{A A}^{p *}\right)^{-1} \Gamma_{A y}^{p} \\
& \frac{\partial \widetilde{A}_{t}}{\partial \widetilde{y}_{t}^{*}} \equiv \eta_{A y^{*}}^{p}=\left(1-\Gamma_{A A}^{p} \Gamma_{A A}^{p *}\right)^{-1} \Gamma_{A y}^{p *} \Gamma_{A A}^{p}
\end{aligned}
$$

For later reference note that $\frac{\partial \eta_{A y^{*}}}{\partial \tau}<0$ and since

$$
\frac{\partial\left(\frac{\eta_{A y^{*}}^{p}}{\eta_{A y}^{p}}\right)}{\partial \tau}=\frac{\partial \phi}{\partial \tau}>0 \quad \text { where } \phi=\frac{\eta_{A y^{*}}^{p}}{\eta_{A y}^{p}}=\frac{\Gamma_{A y}^{p *} \Gamma_{A A}^{p}}{\Gamma_{A y}^{p}}
$$

it is implied that $\frac{\partial \eta_{A y}}{\partial \tau}<0$.

\section{Proof Proposition 5:}

Proceeding as with the proof of proposition 3 we have

$$
\frac{\partial \operatorname{Var}\left(\widetilde{A}_{t} \mid \psi_{t-1}\right)}{\partial \kappa}=2\left(\left(\eta_{A y}^{p}+\rho \eta_{A y^{*}}^{p}\right) \frac{\partial \eta_{A y}^{p}}{\partial \kappa}+\left(\eta_{A y^{*}}^{p}+\rho \eta_{A y}^{p}\right) \frac{\partial \eta_{A y^{*}}^{p}}{\partial \kappa}\right) \sigma^{2}
$$

Since $\frac{\partial \eta_{A y}^{p}}{\partial \kappa}<0$ and $\frac{\partial \eta_{A y^{*}}^{p}}{\partial \kappa}<0$ we can use the same procedure as for the proof of proposition 3 to show that

$$
\frac{\partial \operatorname{Var}\left(\widetilde{A_{t}}\right)}{\partial \kappa}<0 \quad \text { for } \quad \rho \geq \underline{\rho}^{p} \equiv-\phi<0
$$

\section{Proof Proposition 6:}

It follows straightforwardly that

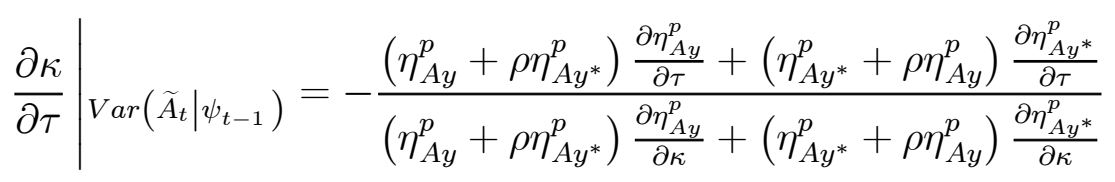


and since both the denominator and nominator are negative for $\rho \geq \rho^{p}$, cf. above, we can conclude that the term on the RHS is negative, and proposition 6 follows.

\section{Proof Proposition 7:}

Minimizing (8) wrt $\kappa$ yields the first order condition

$$
\Phi(\kappa, \pi) \equiv \frac{2 \pi \kappa^{2}}{\left(1+\pi \kappa^{2}\right)}=-\varepsilon_{\operatorname{Var}\left(\widetilde{A}_{t} \mid \psi_{t-1}\right), \kappa} \equiv-\frac{\frac{\partial \operatorname{Var}\left(\widetilde{A}_{t} \mid \psi_{t-1}\right)}{\partial \kappa} \kappa}{\operatorname{Var}\left(\widetilde{A}_{t} \mid \psi_{t-1}\right)}
$$

It follows that the optimal contingency parameter is positive $(\kappa>0)$ since

$$
\begin{aligned}
-\varepsilon_{\operatorname{Var}\left(\widetilde{A}_{t} \mid \psi_{t-1}\right), \kappa} & =-2 \frac{\left(\eta_{A y}^{p}+\rho \eta_{A y^{*}}^{p}\right) \frac{\partial \eta_{A y}^{p}}{\partial \kappa} \kappa+\left(\eta_{A y^{*}}^{p}+\rho \eta_{A y}^{p}\right) \frac{\partial \eta_{A y^{*}}^{p}}{\partial \kappa}}{\left(\eta_{A y}^{p}\right)^{2}+\left(\eta_{A y^{*}}^{p}\right)^{2}+2 \rho \eta_{A y}^{p} \eta_{A y^{*}}^{p}} \\
& =-2\left[\lambda \varepsilon_{\eta_{A y}^{P}, \kappa}+(1-\lambda) \varepsilon_{\eta_{A y^{*}}^{P}, \kappa}\right]>0
\end{aligned}
$$

where

$$
\lambda \equiv \frac{1+\rho \phi}{1+\phi^{2}+2 \rho \phi} \quad ; \quad \frac{\partial \lambda}{\partial \rho}<0 ; \frac{\partial \lambda}{\partial \phi}<0
$$

We have that

$$
\frac{\partial \Phi(\kappa, \pi)}{\partial \kappa}>0 ; \frac{\partial \Phi(\kappa, \pi)}{\partial \pi}>0
$$

From which it follows that $\frac{\partial \kappa}{\partial \pi}<0$.Using that $\eta_{A y^{*}}^{p}=\phi \eta_{A y}^{p}$, where $\phi=\Gamma_{A A}^{p}$ in symmetric equilibrium we have

$$
\begin{aligned}
& \varepsilon_{\eta_{A y^{*}}^{p}, \kappa}=\varepsilon_{\Gamma_{A A}^{p}, \kappa}+\varepsilon_{\eta_{A y}^{p}, \kappa} ; \quad \varepsilon_{\Gamma_{A A}^{p}, \kappa}=\varepsilon_{\Gamma_{A y}^{p}, \kappa} \\
& \varepsilon_{\eta_{A y}^{p}, \kappa}=\left(1+\frac{2}{1-\phi^{2}}\right) \varepsilon_{\Gamma_{A y}^{p}, \kappa}
\end{aligned}
$$

and therefore

$$
-\varepsilon_{\operatorname{Var}\left(\widetilde{A}_{t} \mid \psi_{t-1}\right), \kappa}=-2 \Xi \varepsilon_{\Gamma_{A y}^{p}, \kappa}, \quad \text { where } \quad \Xi(\phi, \rho) \equiv 1+\frac{2}{1-\phi^{2}}+(1-\lambda)
$$

It follows straightforwardly that

$$
\frac{\partial\left(-\varepsilon_{\operatorname{Var}\left(\widetilde{A}_{t} \mid \psi_{t-1}\right), \kappa}\right)}{\partial \rho}=-2 \varepsilon_{\Gamma_{A y}^{P}, \kappa} \frac{\partial \Xi}{\partial \rho}>0
$$


and therefore $\frac{\partial \kappa}{\partial \rho}>0$. Finally, considering trade frictions we have

$$
\operatorname{sign} \frac{\partial \kappa}{\partial \tau}=\operatorname{sign}\left(\frac{\partial \varepsilon_{\operatorname{Var}\left(\widetilde{A}_{t} \mid \psi_{t-1}\right), \kappa}}{\partial \tau}\right)=\operatorname{sign}\left[-2\left[\Xi \frac{\partial \varepsilon_{\Gamma_{A y}^{p}, \kappa}}{\partial \tau}+\varepsilon_{\Gamma_{A A}^{P}, \kappa} \frac{\partial \Xi}{\partial \tau}\right]\right]
$$

Note that

$$
\begin{aligned}
& \frac{\partial \varepsilon_{\eta_{A y}^{p}, \kappa}}{\partial \tau}>0 \\
& \frac{\partial \Xi}{\partial \tau}=\frac{-4 \phi}{\left(1-\phi^{2}\right)^{2}}+\frac{2 \phi+\rho+\rho \phi^{2}}{\left(1+\phi^{2}+2 \rho \phi\right)^{2}} \gtreqless 0
\end{aligned}
$$

We have that $\frac{\partial \kappa}{\partial \tau}<0$ when $\frac{\partial \Xi}{\partial \tau}<0$. We shall prove that $\phi>\underline{\phi}\left(<\frac{1}{2}\right)$ is a sufficient condition that $\frac{\partial \Xi}{\partial \tau}<0$ for $\rho \in[0,1]$. $\underline{\phi}$ is defined by $\left(1+\underline{\phi}^{2}\right)^{2}-$ $8 \underline{\phi^{2}}=0$. To this end first note that

$$
\begin{aligned}
& \left.\frac{\partial \Xi}{\partial \tau}\right|_{\rho=0}=\frac{-4 \phi}{\left(1-\phi^{2}\right)^{2}}+\frac{2 \phi}{\left(1+\phi^{2}\right)^{2}}<0 \\
& \left.\frac{\partial \Xi}{\partial \tau}\right|_{\rho=1}=\frac{-4 \phi}{\left(1-\phi^{2}\right)^{2}}+\frac{1}{\left(1+\phi^{2}+2 \phi\right)}<0 \text { for } \phi>\underline{\phi}
\end{aligned}
$$

Since

$$
\frac{\partial}{\partial \rho} \frac{\partial \Xi}{\partial \tau}<0 \quad \text { for } \phi>\underline{\phi} \text { and } \rho \in[0,1]
$$

and $\phi$ is increasing in $\alpha$, proposition 7 follows.

\section{References}

Agell, J., 1999, On the Benefits from Rigid Labor Markets: Norms, Market Failures, and Social Insurance, Economic Journal, 109 (supplement), 143-164.

Andersen, T.M., B.S. Rasmussen and J.R. Sørensen, 1996, Optimal Fiscal Policy in Open Economies with Labour Market Distortions, Journal of Public Economics, 63, 103-117.

Andersen, T.M., and R.R. Dogonowski, 2001, The Public Budget and Social Insurance, Economica (to appear). 
Andersen, T.M. and S. Holden, 2001, Stabilization Policy in an Open Economy, Journal of Macroeconomics (to appear)

Atkinson, T., 1999, The Economic Consequences of Rolling Back the Welfare State, Munich Lectures in Economics, CES. MIT Press.

Boix, C., 1998, Political Parties, Growth and Equality: Conservative and Social Democratic Economic Strategies in the World Economy, Cambridge University Press.

Braconier, H. and S. Holden, 1999, The Public Budget Balance, Fiscal Indicators and Cyclical Sensitivity in the Nordic Countries, Tema Nord 1999: 575, Nordic Council of Ministers.

Coppel, J. and M. Durand, 1999, Trends in Market Openness, OECD Working Paper, No. 221.

Devereux, M.B., 1991, The Terms of Trade and International Coordination of Fiscal Policy, Economic Inquiry, 29, 720-736.

Esping-Andersen, G., 1990, The Three Worlds of Welfare Capitalism, Policy Press.

Esping-Andersen, G., 1999, Social Foundations of Postindustrial Economies, Oxford University Press.

Frankel, J.A. and A.K. Rose, 1988, The Endogeneity of the Optimal Currency Area Criteria, Economic Journal, 108, 1008-1025.

Glick, R. and K. Rogoff, 1995, Global vs. Country-Specific Productivity Shocks and the Current Account, Journal of Monetary Economics, 35, 159-162.

Lewis, K., 1999, Trying to explain Home Bias in Equilibrium and Consumption, Journal of Economic Literature, XXXVII, 571-608.

Obstfeld, M. and K. Rogoff, 2000, New Directions for Stochastic Open Economy Models, Journal of International Economics, 50, 117-153.

OECD, 1999, EMU: Facts, Challenges and Policies, Paris.

Razin, A., 1995, The Dynamic Optimization Approach to the Current Account: Theory and Evidence, CEPR Discussion Paper 797.

Rodrik, D., 1997, Has Globalization Gone too Far?, Institute for International Economics, Washington. 
Rodrik, D., 1998, Why do More Open Economies Have Bigger Governments? Journal of Political Economy, 106, 997-1032.

Sandmo, A., 1995, Introduction: Welfare Economics of the Welfare State, Scandinavian Journal of Economics, 97, 469-476.

Sinn, H.-W., 1995, A Theory of the Welfare State, Scandinavian Journal of Economics, 97, 495-526.

Stockman, A.C. and L.L. Tesar, 1995, Tastes and Technology in a Twocountry Model of the Business Cycle: Explaining International Comovements, American Economic Review, 85, 108-185.

Sørensen, P.B., 2000, The Case for International Tax Co-ordination Reconsidered, Economic Policy, 31, 431-472.

Swank, D., 1999, Political Institutions and Welfare State Restructuring, Marquette University.

Turnovsky, S.J., 1988, The Gains from Fiscal Cooperation in a Two-Country Trade Model, Journal of International Economics, 25, 111-127.

van der Noord, 2000, The Size and Role of Automatic Stabilizers in the 1990s and Beyond, OECD Working Paper 230.

van der Ploeg, F., 1987, Coordination of Optimal Taxation in a TwoCountry Equilibrium Model, Economics Letters, 24, 279-285.

Wildasin, D.E., 1995, Factor Mobility, Risk and Redistribution in the Welfare State, Scandinavian Journal of Economics, 97, 527-546.

Wildasin, D.E., 2000, Labor-Market Integration, Investment in Risky Human Capital and Fiscal Competition, American Economic Review, 90, 73-95. 


\section{IZA Discussion Papers}

No.

Author(s)

G. Bertola

S. Hochguertel

W. Koeniger

441

C. W. Sibley

P. P. Walsh

M. Lindahl

R. Lalive

J. Zweimüller

M. Fertig

C. M. Schmidt

E S.Pra

B. R. Chiswick

P. W. Miller

Y. L. Lee

P. W. Miller

B. R. Chiswick

Y. Liang Lee

P. W. Miller

P. Carneiro

K. T. Hansen

J. J. Heckman

J. T. Addison

C. R. Belfield
Title

Area

Date

Dealer Pricing of Consumer Credit

7

$02 / 02$

Earnings Inequality and Transition: A Regional 4

Analysis of Poland

Estimating the Effect of Income on Health and Mortality Using Lottery Prizes as Exogenous

Source of Variation in Income

Identifying Functional Labour Market Areas in

New Zealand: A Reconnaissance Study Using

Travel-to-Work Data

Benefit Entitlement and the Labor Market:

6

$02 / 02$

Evidence from a Large-Scale Policy Change

Informational Cascades and Decision to Migrate 1

$03 / 02$

Macroeconomic Policy Lessons of Labor Market 6

$03 / 02$

Frictions

Mobility within Europe - What do we (still not) 6 know?

Inequality, Transfers and Growth: New Evidence from the Economic Transition in Poland

Do Enclaves Matter in Immigrant Adjustment?

Schooling, Literacy, Numeracy and Labor

$03 / 02$ Market Success State
The Complementarity of Language and Other Human Capital: Immigrant Earnings in Canada$$
\text { P. W. Miller }
$$

Longitudinal Analysis of Immigrant Occupational 1 Mobility: A Test of the Immigrant Assimilation Hypothesis

Removing the Veil of Ignorance in Assessing the 6

Distributional Impacts of Social Policies

Defensive Innovations

Unions and Establishment Performance:

3

03/02

Evidence from the British Workplace Industrial/

Employee Relations Surveys

International Integration, Risk and the Welfare

$03 / 02$

T. M. Andersen 